Chapter 11

\title{
Vascular Anomalies of the Maxillofacial Region: Diagnosis and Management
}

\author{
Faris Fočo and Amila Brkić \\ Additional information is available at the end of the chapter \\ http://dx.doi.org/10.5772/53853
}

\section{Introduction}

Vascular anomalies are heterogeneous group of congenital lesions of abnormal vascular development and may occur anywhere on the body. There is a primary distinction between a vascular tumor, which grows by cellular hyperplasia, and a vascular malformation, which represents a localized defect in vascular morphogenesis. Due to the differences in biologic behavior and radiographic features, malformations are further subdivided into low-flow and high-flow lesions [1]. The common characteristic feature of all vascular anomalies is extreme bleeding during surgical excision. Clinicians throughout the world use the classification by Mulliken and Glowacki (1982) to classify these lesions. This classification is based on the vascular lesion's histology, biological behavior and clinical findings [2]. Some of the lesions cause esthetic problems, while some of them are malignant; thus, the therapeutic approach is variable.

\begin{tabular}{ll}
\hline Vascular tumors & Vascular malformations \\
\hline Infantile hemangioma & Slow-flow \\
\hline Congenital hemangioma & Capillary malformations \\
\hline Tufted angioma & Venous malformations \\
\hline Kaposiform hemangioendothelioma & Lymphatic malformations \\
\hline & Fast-flow \\
\hline
\end{tabular}

Table 1. Classification of vascular anomalies by Mulliken and Glowacki.

One of the most seen vascular tumors involving the head and neck region are hemangiomas. These benign, generally painless lesions, are a proliferating mass of blood vessels that do not 
undergo malignant transformation; $60 \%$ percent of cases are localized in the head and neck region. The rest are located in the trunk area (5\%) and the extremities $(15 \%)[3,4]$. Hemangiomas are mostly seen on the surface of the skin, although internal organs such as the liver, larynx, lung or gastrointestinal tract may be also be affected. In the oral cavity, they may occur on the tongue, lips, buccal mucosa, gingiva, palatal mucosa, salivary glands, alveolar ridge and jaw bones $[5,6]$. In the majority of patients hemangiomas occure as a single lesion, however $20 \%$ of patients may have more than one hemangioma [7].

In the literature, multiple hemangiomas are described as one of the components of so called „PHACES“ syndrome. The syndrome includes: Posterior fossa defects, Hemangiomas, Arterial abnormalities, Coarctation of the aorta and cardiac malformations, Eye anomalies, and Sternal defects [8].

In this chapter we will try to describe and document the clinical features and management of the head and neck hemangiomas.

\section{Hemangiomas}

The term hemangioma was originally used to describe any vascular tumor-like structure, whether it was present at or around birth or appeared later in life. The term is comprised of the Greek words "haema" which means blood, "angeio" meaning vessel and "oma" meaning tumor. Histologically hemangiomas are composed of hyperplastic endothelial cells, which are line the inner surface of the blood vessels in the human body, with the capacity for intensive proliferation. The diameter of the blood vesels is important in classification of hemangiomas to capillary and cavernous types [9]. The capillary type, also known as the strawberry hemangioma is composed of small thin-walled vessels of capillary size that are lined by a single layer of flattened or plump endothelial cells and surrounded by a discontinuous layer of pericytes and reticular fibers $[9,10]$ (Figures 1and 2). It was first described in the literature in 1973 by Sznajder et al.[11], under the term "Hemorrhagic hemangioma" [10].

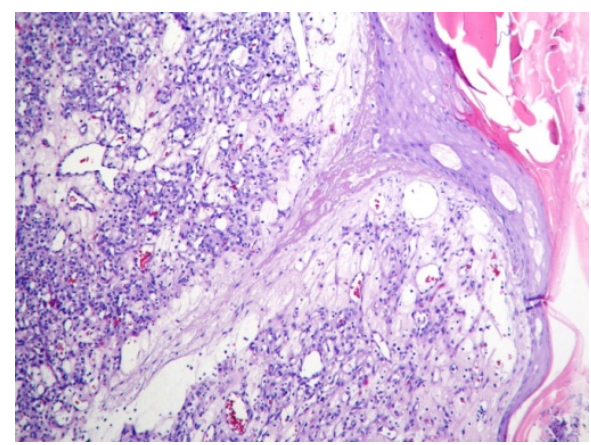

Figure 1. Capillary lip hemangioma 


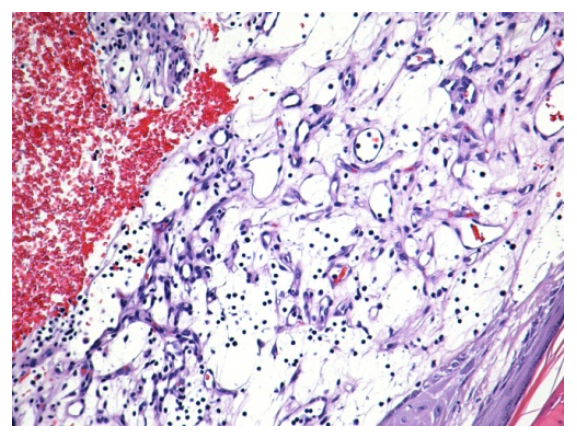

Figure 2. Capillary lip hemangioma 20X

The cavernous type is characterized by large blood-filled spaces, so called cavities, that are separated by a scanty connective tissue stroma [9]. Some lesions of hemangiomas are mixed, which means that they have histologic components of both types [10] (Figures 3 and 4).

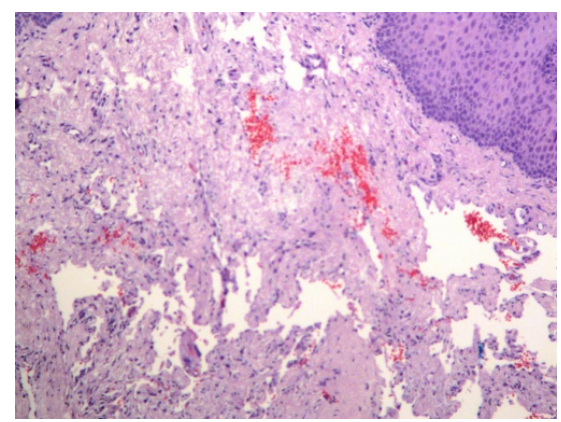

Figure 3. Cavernous lip hemangioma

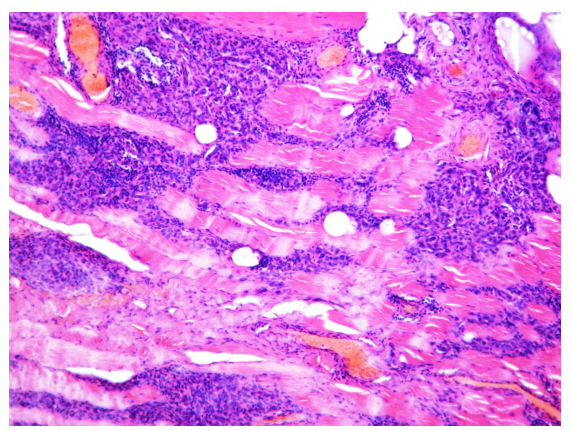

Figure 4. Capillary hemangioma of lips 20X 
Clinically, hemangiomas are characterized as a soft, smooth or lobulated, sessile or pedunculated mass and may be seen in any size from a few millimeters to several centimeters [12]. The color of the lesion ranges from pink to red or purple and blanches on the application of pressure; hemorrhage may occur either spontaneously or after minor trauma [3]. Hemangiomas are subdivided into two types: "infantile" and "congenital" $[1,13]$. However, there is a hypothesis that these two entities are the variations of a single entity ab initio [14].

\subsection{Infantile hemangiomas}

Infantile hemangiomas are the most common tumors of infancy and occur in approximately $10 \%$ of infants by the age of 1 year, with a female predominance [15]. Studies suggest that the ratio between female-male is 3-5:1, and a higher prevalence is seen in cases of premature neonates especially when their weight at birth is less than $1500 \mathrm{~g}$. [4,10]. As we mentioned before, the most common localization of hemangiomas is the surface of the skin; thus, hemangiomas usually appear as a barely visible pale, spot, red stain macula, telangiectatic or pseudoecchymotic patch, 2-4 weeks after birth. Massive life threatening lesions usually occur in the liver or central nervous system [16].

Infantile hemangiomas consist of rapidly dividing endothelial cells [13]. Chang et al. [10] state that growth of infantile hemangiomas pass through 3 phases; Proliferation, involuting and involuted phases. The proliferative phase is characterized by rapid growth of the hemangioma during the first year of life. A cellular mass without a defined vascular architecture and nascent blood vessels with red blood cells are evident within the lumen [17]. This phase is the most pronounced during the first 3 - 6 months. However, it may be followed by a phase of slower growth. Regardless of subtype or depth, hemangiomas reach an average of $80 \%$ of their final size during the early proliferation stage, a stage that ends at a mean age of 3.2 months. Infantile hemangiomas at the beginning of the proliferation phase, can show an early or late proliferation growth pattern. This means that in cases with an early proliferation growth pattern proliferation starts earlier and essentially is complete after 5 months of age. While In cases of late proliferation growth, proliferation starts later and lasts longer [10] (Figures 5A and 5B).

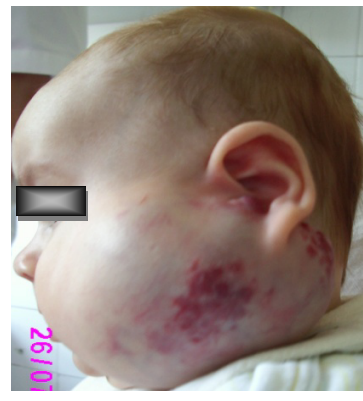

(A)

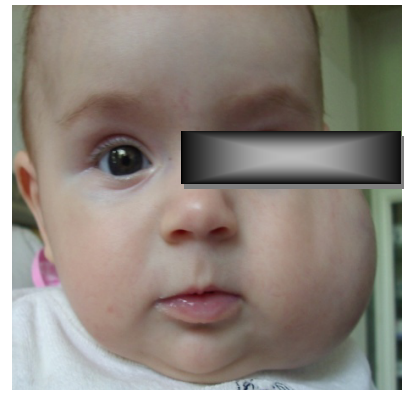

(B)

Figure 5. A) Infantile hemangioma of the cheek. (B) Frontal view 
The involuting phase follows the previous phase; thus in some cases it starts in a few months, while in most cases by 12-18 months of age [10] and continues for 3 to 5 years [17]. Proliferation slows or stops in this phase, and histologic examination shows that the blood vessel architecture becomes more obvious and vessel size enlarges [17]. It is important to mention that in some cases different parts of the hemangioma may be under proliferation and involuting at the same time [10]. Clinical signs of involution are characterized by a color change from bright red to dull red to gray and usually begins centrally and spreads out over the lesion with time. Generally, involution takes place at an estimated rate of $10 \%$ per year, so that approximately $50 \%$ have involuted by 5 years of age, $70 \%$ by 7 years, and $90 \%$ by 9 years [10]. The involuted phase is the third phase in the hemangiomas and occurs at 5 to 8 years of age, at which point blood vessels are replaced with a fibrofatty residuum and capillary-sized channels [17]. In this phase depending on the size of the hemangiomas the form changes and may include restoration to normal skin (in 50\%) or fibro-fatty form of hemangioma residuum and redundant skin. The later a hemangioma starts to involute, the higher is their risk for residual changes after involution is completed. An involuted hemangioma will never start to grow again; tumor growth in the completed involution phase is always finished [10]. Glucose transporter-1 (GLUT-1) has been shown to be a specific marker for endothelium in all phases of infantile hemangioma, comparing with congenital hemangiomas, in which this marker has not been detected [18,19].

\subsection{Congenital hemangiomas}

Congenital hemangiomas are fully developed at birth which do not exhibit accelerated postnatal growth. They may be diagnosed on a prenatal ultrasound. In 2000, congenital hemangiomas were identified as rapidly involuting congenital hemangiomas (RICH) and noninvoluting congenital hemangiomas (NICH) $[10,13]$. Both subtypes have many similarities, such as appearance, location, size, and sex distribution [14,18]. Also they have some overlapping histologic features with infantile hemangioma [18].

\subsubsection{Rapidly involuting congenital hemangiomas}

Rapidly involuting congenital hemangiomas ( $\mathrm{RICH})$ are also present at birth as protuberant, hemispherical, violaceous tumors with an average diameter of 5-6 centimeters, that often have a central depression, scar or ulceration [18]. Histologic features are variable including large and small lobules separated by dense fibrous tissue, and in some lesions there is a sponge-like network of large capillaries [18]. RICH goes through a rapid regression phase and may be completely gone by the time the child is 12 to 18 months old, leaving a mark as some degree of atrothic or redundant skin [20]. In some cases rapidly involuting congenital hemangiomas can undergo rapid but incomplete involution, with a resulting clinical appearance and histology similar to noninvoluting congenital hemangiomas. Because of this, it has been suggested that RICH and NICH may lie within the same spectrum of vascular tumors $[14,18,20]$. Rapidly involuting congenital hemangiomas are usually located on the limb, head and neck regions and may be associated with decreased gioplatelets, thought to be due to localized intravascular coagulation [21]. 


\subsubsection{Non-involuting congenital hemangiomas}

Noninvoluting congenital hemangioma $(\mathrm{NICH})$ is present at birth, grows proportionately with the child, exhibits persistent fast-flow and does not regress [18]. This lesion occurrs more often in male patients. Usually it is a single lesion with an average diameter of $5 \mathrm{~cm}$. Shapes may vary from round-to-ovoid or plaque-like, while the color may also be a variable from pink to purple $[18,22]$. The overlying skin is frequently punctuated by coarse telangiectasia, often with central or peripheral pallor [22] (Figures 6A and 6B).

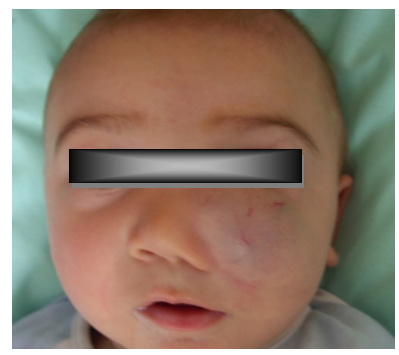

(A)

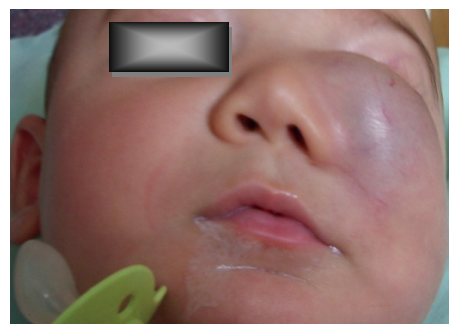

(B)

Figure 6. A) Congenital hemangioma. (B) Frontal view

Histologically, NICH is characterized by lobules with high cellular density: each lobule contains one or more large, irregular intralobular vessels surrounded by multiple small vessels with indistinct lumens [18].

\begin{tabular}{|c|c|}
\hline Congenital hemangioma & Infantile hemangioma \\
\hline Present at birth. & Visible between 2 weeks and 4 months of age. \\
\hline $\begin{array}{l}\text { Growth is complete at birth or may grow proportionately } \\
\text { as the child grows. }\end{array}$ & $\begin{array}{l}\text { Grows rapidly for about } 6 \text { to } 12 \text { months (average is around } \\
8 \text { months). }\end{array}$ \\
\hline Males : females $=1: 1$ & Males : females $=1: 3-5$ \\
\hline Less common but not rare. & Common [4-5 percent incidence in newborns). \\
\hline Rapid or no involution (shrinking). & Slow shrinking that takes months or years. \\
\hline GLUT-1 negative & GLUT-1 positive \\
\hline $\begin{array}{l}\text { Proliferating phase characterized by large and irregularly } \\
\text { shaped vessels }\end{array}$ & $\begin{array}{l}\text { Proliferating phase characterized by small regular } \\
\text { capillaries }\end{array}$ \\
\hline
\end{tabular}

Table 2. Differences between congenital hemangioma and infantile hemangioma 


\section{Etiology}

Hemangioma development is also known as hemangiomagenesis [23]. Although pathogenesis and origin of hemangioma remains incompletely understood, medical literature describes different hypothesis for its development in which extrinsic and intrinsic factors play an important role of endothelial cell proliferation. Placental, estrogen signaling, genetic theory, theory of hypoxia and role of the growth factors involved in angiogenesis such as vascular endothelial growth factor (VEGF), tissue growth factor beta (TGF-beta) and insulinlike growth factor-2 (IGF-2), are just some of theories of hemangioma development.

\subsection{Placental origin theory}

In the placental theory, there is an opinion that the infantile hemangioma originated from placental trophoblast [23-25]. The hypothesis is based on shared expression of distinct endothelial markers such as GLUT1, Fc $\gamma$ RII, $\alpha$ 2-laminin, Lewis Y antigen, type III iodothyronine deiodinase, indoleamine 2,3-deoxygenase, and insulin-like growth factor 2 in the placenta and hemangioma [22]. Also an incidence of hemangiomas occurrence is more common in infants born to mothers with placental abnormalities, such as preeclampsia and placenta previa, as well as those exposed to chorionic villous sampling (CVS)[26,27], which once more contribute to the placental theory of hemangioma development.

\subsection{Estrogen signaling theory}

Estrogen signaling theory suggests that because of increased incidence in females, evidence of estrogen receptor (ER) positivity in endothelian cells of proliferating hemangiomas, and elevated levels of circulating 17- $\beta$ estradiol (which is known to be protective for hypoxiainduced apoptosis) in affected children, the estrogen may be involved in the growth of infantile hemangioma $[16,28]$. In the perinatal period free estrogen increases, which may stimulate areas of hypoxic endothelium to induce hemangioma formation [16,29].

\subsection{Hypoxia theory}

In the hypoxia theory, the hypoxic environment leads to an upregulation of factors that promote the recruitment and proliferation of endothelial progenitor cells. These factors include; hypoxia inducible factor-1alpha (HIF-1alpha), stromal cell derived factor-1alpha (SDF-1alpha) and vascular endothelial growth factor (VEGF) [18,27]. However,in this theory there is link between hypoxia and estrogen contribution in hemangioma formation. In explanation, increased estrogen hormone levels in the postpartum period create a milieu that promotes new blood vessel development and growth of the lesion $[27,29]$.

\subsection{Theory of angiogenesis involved growth factors}

Growth factors specifically involved in angiogenesis such as vascular endothelial growth factor(VEGF), insulin-like growth factor-2 (IGF-2) and tissue growth factor beta (TGF-beta) are often increased during the proliferation phases of hemangioma growth; while 
during the involution phase of hemangioma, they decrease [30].Vascular endothelial growth factor (VEGF) was originally identified as an endothelial cell specific growth factor stimulating angiogenesis and vascular permeability $[18,29]$. Studies suggest that in the patients with proliferating hemangiomas, the serum vascular endothelial growth factor concentrations are significantly higher than in patients with involuting hemangiomas, vascular malformations and healthy patients [18,31,32]. Insulin-like growth factor-2 (IGF-2) is known to be highly expressed in infantile and congenital hemangiomas[19]. Links between this factor and angiogenesis would be that IGF-2 induce hypoxia-inducible factor $1-\alpha$ (HIF-1 $\alpha$ ), and HIF-1 $\alpha$ is known to up-regulate glucose transporter-1 (GLUT-1) [18]. However, GLUT-1 is specific only for infantile hemangiomas [19]. An expression of tissue growth factor beta (TGF-beta) in proliferative hemangioma is significantly higher comparing with the other stages of hemangiomas [33,34].

\subsection{Genetic theory}

In the genetic theory, a hereditary component is presumed to be the cause of hemangiomas $[34,35]$. Hemangioma may be passed from parent to child as an autosomal dominant trait with incomplete penetrance [35]. Although the gene responsible for hemangioma/malformation development is not identified, there is an opinion that the gene locus could be on chromosome $5 q$ [34]. Genetics and race may play an important role in hemangiomas occurrence, due to the fact that the majority of hemangiomas occur in infants of Caucasian descent, rarely in Asian and almost never occur in infants of African-American descent $[4,36]$.

\section{Clinical findings}

The majority of hemangiomas are located on the skin as a soft, smooth or lobulated, sessile or pedunculated masse. Their size may vary from several millimeters to several centimeters $[1,3]$. The color of the lesions range from pink to red purple and tumors blanch on the application of pressure [3]. Hemangiomas can be superficial, deep, or compound [1]. The superficial hemangioma (affecting only the superficial skin) is red and nodular with no subcutaneous component. A deep hemangioma (affecting only the deep skin) presents as a protrusion with an overlying bluish tint or telangectasia. Compound (mixed) hemangioma has both deep and superficial components [1,10]. By statistics, $60 \%$ of hemangiomas are superficial, $15 \%$ are deep, and $25 \%$ are compound [10].

More than $80 \%$ of hemangiomas are solitary lesions [7]. Hemangiomas may be further subdivided into focal, multifocal and segmental hemangiomas. Focal hemangiomas are localized, unilocular lesions which adhere to the phases of growth and involution. Multifocal hemangiomas usually involve a visceral organs, while segmental hemangiomas are more diffuse plaque-like and can lead to untoward functional and esthetic outcomes [1]. Deep segmental hemangiomas proliferate longer, while superficial and focal hemangiomas start to involute earlier [10]. 
In $60 \%$ percent of cases hemangiomas are localized in the head and neck region with the distribution of the trigeminal nerve $[1,3,4]$. They can be localized even in the infraorbital nerve canal [37].A beard-like distribution is associated with a subglottic hemangioma [1]. In cases of deeply located hemangiomas such as those in eye, symptoms might be amblyopia (lazy eyes) and distortion of the cornea. Hemangiomas in the respiratory system can block breathing, while those located in the liver may be asymptomatic, unless due to huge size stresses the heart. In the oral region, hemangiomas are not that common. If they are present, they may occur on tongue (Figure 7), lips, buccal mucosa, gingiva, palatal mucosa, salivary glands, alveolar ridge and jaw bones $[3,5,6]$.

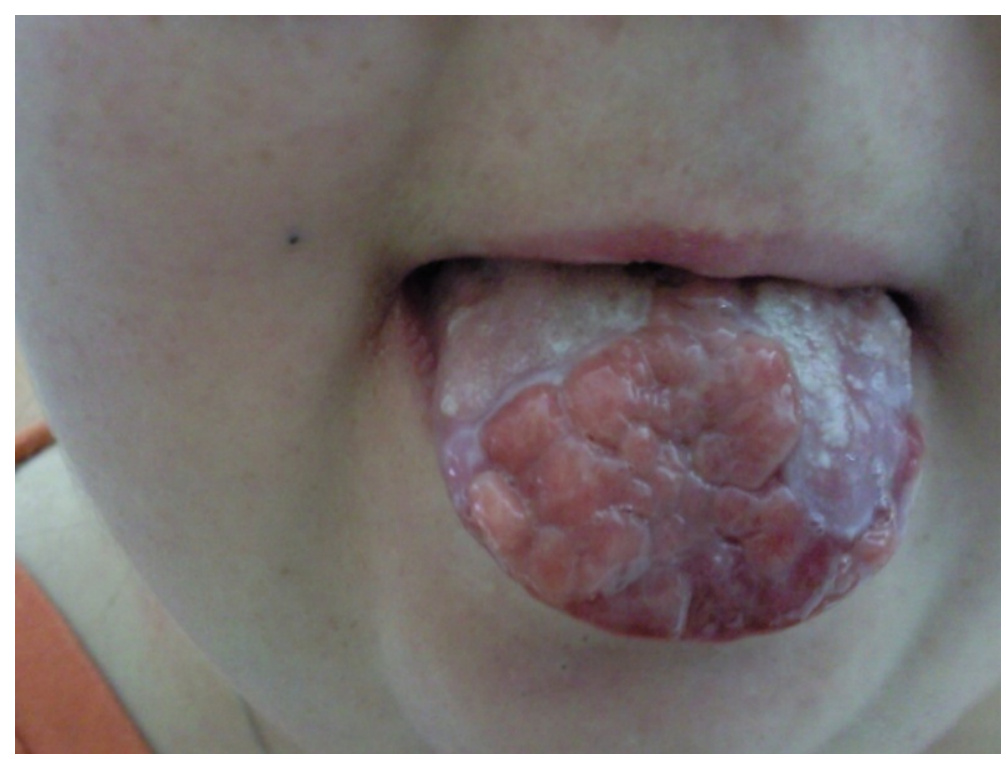

Figure 7. Hemangioma of the tongue.

In cases of gingival hemangiomas, the lesions often appear to arise from the interdental gingival papilla and spread laterally to involve adjacent teeth [3]. Masticatory trauma plays an important role in development of symptoms such as bleeding of the gingiva or tongue. In hemangiomas of the jaw, clinical signs usually develop after extraction of tooth associated with the lesion. Oral bleeding may be spontaneous in cases that violate the epithelial basement membrane by penetration of the hemangioma [38].

\subsection{Diagnosis}

The diagnosis of a hemangioma is based on clinical history, physical, radiographic, laboratory and pathohistological examinations. In previous parts of the chapter we have described clinical and histological findings of hemangiomas. 
Radiographic examinations are usually performed in cases of deeply positioned hemangiomas. The examinations include conventional radiography with panoramic radiographs, angiography, computed tomography (CT), magnetic resonance imaging (MRI) and Doppler ultrasonography. Conventional radiography is used mostly for diagnosis of bone hemangiomas. Findings are multicystic "soap bubble" appearances. On CT the changes are in bone trabeculae. In diagnosis of soft tissue hemangiomas CT, MRI and Doppler ultrasonography are performed. MR imaging can be used to classify vascular malformations as either lowflow or high-flow lesions, especially when combined with dynamic contrast-enhanced MR angiography. Also, evaluation of extraosseous extension can be diagnosed by MRI [39]. Doppler ultrasonography is the least invasive and most cost-effective imaging to document blood flow in hemangiomas.

Pathohistological examinations for diagnosis and distinguishing hemangiomas from other lesions sometimes do not offer a proper diagnosis. For example in the differential diagnosis from oral pyogenic granuloma, both lesions share the histologic designation "capillary hemangioma“" [38].

Laboratory examinations are important in differential diagnosis of hemangiomas to the other arteriovenous malformations and pathologies. Glucose transporter-1 (GLUT-1), vascular endothelial growth factor (VEGF), insulin-like growth factor-2 (IGF-2) and tissue growth factor beta (TGF-beta) are just some of the examinated factors. For example, as we mentioned before, positive staining for GLUT-1 is considered highly specific and diagnostic for hemangioma, and it is useful for making differential diagnosis between hemangioma and other vascular lesions clinically related to it [12].

\subsection{Differential diagnosis}

Differential diagnosis of the head and neck hemangiomas include several lesions such as pyogenic granuloma, chronic inflammatory gingival hyperplasia, epulis granulomatosa, telangiectasia, angiosarcoma, squamous cell carcinoma, and other vascular appearing lesions such as Sturge Weber syndrome.

Rapidly involuting congenital hemangioma ( $\mathrm{RICH})$ as single large tumor associated with lesional ulceration and congestive heart failure, can easily be confused with congenital infantile fibrosarcoma and arteriovenous malformation [19]. Because of this, arteriography in order to exclude infantile fibrosarcoma and arteriovenous malformation play an important role in proper diagnosis. In these cases biopsy is not advantageous because of the high risk of bleeding. It may be reasonable only in cases of previously reported congenital infantile fibrosarcoma [19].

Noninvoluting congenital hemangioma $(\mathrm{NICH})$ may vary from plaque-like with a pink or purple color, to prominent overlying coarse telangiectasias, and be difficult to diagnosed or distinguish from the other, even malignant pathologic lesions [20].

The differentiation between hemangioma and vascular malformations is made on the basis of clinical appearance, histopathology, and biological behaviour [12]. 


\section{Complications}

Complications associated with hemangiomas may include;bleeding, ulceration, infection, airway obstruction or visual complications. The incidence of complications such as ulceration is between $5-13 \%$ [3]. Ulceration usually occurs in the proliferative phase because the growth of the lesion surpasses epidermal elasticity and blood supply. Large lesions and lesions in the area of the skin flexion such as intertriginous, perineal, and perioral are more prone to develop ulcerations $[8,26]$. Bleeding and infection development are in many cases just sequels of ulceration [8]. In the oral region bleeding and infection may develop after masticatory minor trauma. Airway obstruction is caused by hemangiomas located in the respiratory system. Infantile hemangioma lesions in a "beard-like" distribution along the jaw are at increased risk of airway involvement. These infants, therefore, need to be monitored frequently for signs of respiratory distress, including a barking cough and/or progressive stridor, especially during the first several months of life [8]. Amblyopia "lazy eyes" and distortion of the cornea are complications associated with periocular-located hemangiomas $[8,26]$. Strabismus, myopia, tear duct obstruction, proptosis, and ptosis are other complications associated with the ocular hemangiomas [8].

\section{Management}

Management of hemangiomas include sevaral factors including age of the patient, type, size, dissemination and depth of penetration $[3,12]$. There is an opinion that only $10-20 \%$ of hemangiomas due to the size, location, stages of growth or regeneration, functional compromise and behaviour, require treatment [12]. For example a large lesions prone to ulceration, bleeding, infection, vital and functional compromises must be treated. Treatment options include: surgery, laser surgery, local and systemic use of corticosteroids, Interferon alfa, Imiquimod, Propranolol, Pingyangmycin. Each treatment modality has its own risks and benefits [12].

\subsection{Surgery}

Surgical approach to hemangiomas is still the most performed procedure, isolated or in combination with another treatment modalities. Although in more than $80 \%$ of hemangiomas the observation is suggested, due to spontaneous involution of the lesions, in some cases such as lip hemangiomas the "wait and see" approach [40] is not welcome. Lip hemangiomas are highly visibile, prone to ulcerations and have a tendency to a leave residual deformity even after resolution $[40,41]$. Ulcerations are mostly seen during the proliferative period and can lead to increased scarring, loss of lip contour, and disfigurement [41]. The mentioned authors [40,41] stated benefits of early surgical excision of lip hemangiomas. Even lip hemangiomas that cross the vermiliocutaneous junction can be excised and lip contour achieved without the need to extend scars beyond the junction [41]. It is worth mention that in a study by Chang et al. [41], a higher incidence of lower lip hemangiomas, comparing with hemangiomas located in the upper lip was reported. In cases of localized cutaneous infantile hemangiomas, surgical excision is also 
suggested to be performed to minimize the scar after the involuted hemangioma [42,43]. As we know, in proliferative phase, the hemangioma acts like a tissue expander, destroying elastic fibers or causing ulceration resulting in telangiectases, cutaneous laxity, scarring, and fibrofatty residuum [42]. Two types of surgical excisions named lenticular and circular, may be performed in therapy of hemangiomas [42-44]. Lenticular excision of hemangiomas results in increased scar length as compared with the original lesion [43], while circular excision and purse-string closure reduces both the longitudinal and transverse dimensions and converts a large circular lesion into a small ellipsoid scar [42-44]. Also another advantage of the circular excision is minimal distortion of surrounding structures [42]. Vlahovićet al. concluded that the circularexcision and pursestring suture technique are applicable for hemangioma at any stage [44]. In 1985, Popescu [45], presented a new approach to cavernous haemangioma in different sites, which included an intratumoral ligation. The technique completely interrupted the intratumoral blood flow, resulting in obstruction of vascular lumina, endothelial atrophy, blood clot organization in the small diverticula between them and also subsequent fibrous hyperplasia. In this way the hemangioma mass was split into segments, thus the blood flow was eliminated (Figures 8A and 8B).

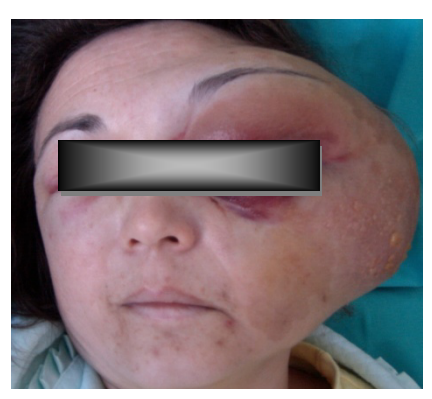

(A)

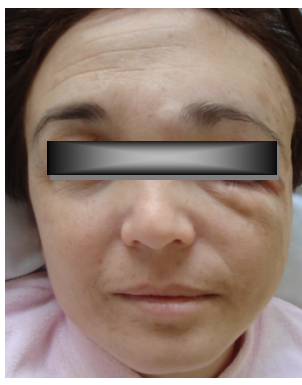

(B)

Figure 8. A) Preoperative view of the patient with diagnosed congenital hemangioma.(B) Postoperative view.

High vascularization of hemangiomas is one of reasons why these lesions are prone to bleeding spontaneously or during the trauma. In the case of head and neck hemangiomas, ligations of the external carotid, facial artery and afferent vessels of the tumour with the aim of decreasing blood supply to the vascular dilatations and channels are performed. However, the results are not so good. In the 1990's a new method of coagulation in cavernous hemangiomas was presented [46]. The use of percutaneous copper needles to induce therapeutic coagulation in cavernous hemangiomas, followed by surgery was effective in cases of facial, cervical and oral hemangiomas [47]. The method [46] was presented as a simple, safe and effective treatment for cavernous hemangiomas.

\subsection{Laser surgery}

From the last few decades, laser surgery has emerged as one of the most performed therapeutic approaches for vascular lesions and hemangiomas. During the 1980's, lasers such as 
argon and carbon dioxide were mostly used for the excision of capillary / cavernous hemangiomas because of the low incidence of bleeding [48]. From 1990's the neodymium: ytriumaluminum-garnet (Nd:YAG) laser started to be in used as a new and effective mode of treatment for vascular lesions [49,50]. Intralesional photocoagulation is the base of the Nd:YAG laser efficacy. Many studies [49-53] evaluated hemangioma outcomes after laser treatment. After a follow up of at least 6 months, reduction in lesion size was noted, especially in cases of large lesions. The authors concluded that the Nd:YAG laser is a safe and effective tool for the treatment of large lesions [49,50]. However, complications such as superficial ulceration or scarring, may be expected [51]. In some cases due to the fact that hemangioma formations do not involute completely, surgical resection or treatment of local steroid injections due to lesion fibrosis may be performed [53].

\subsection{Cryotherapy}

Superficial cryotherapy with carbon dioxide snow may be effective in the case of facial hemangioma, but this method is completely ineffective in the management of tuberous or cavernous haemangiomas [46].

\subsection{Corticosteroids}

In conservative therapy of hemangiomas, the corticosteroids are the first choice. They can be used systemic or locally. Growth disturbance and risk of malformation in children is associated with the use of corticosteroids [46].

\subsubsection{Systemic corticosteroids}

Prednisone as the representative of systemic corticosteroids has found its place in hemangioma treatment. Although the mechanism of action is unknown, there are suggestions that corticosteroids inhibit the expression of VEGF-A by hemangioma-derived stem cells and silencing of VEGF-A expression in these cells inhibited vasculogenesis in vivo [54]. Also they may be responsible for vasoconstriction of arterioles and precapillaries [55]. Daily doses are usually $2-4 \mathrm{mg} / \mathrm{kg}[56,57]$ and it is mostly in use for treatment of cutaneous infantile hemangiomas. Parotid hemangiomas for example may be resistant to this therapy [56]. Reasons for this may be differences in drug metabolism, caliber of blood vessels, and/or blood flow in the parotid gland [56].Benett et al. [57] in their study revealed that the dose of the drug plays an important role in the lesional response, thus higher doses show significantly higher responses and results are more visible, if initiated during the initial proliferative phase. Systemic corticosteroids are mostly in use for treatment of large and aggressive lesions.

The long duration of therapy made it difficult to determine the effect the corticosteroid therapy had on the hemangiomas vs spontaneous involution [57]. Systemic corticosteroids carry well-documented risks, such as disseminated varicella and herpes infections, and some authors have questioned their efficacy [47]. 


\subsubsection{Local corticosteroids}

Local corticosteroids in the form of intralesional corticosteroid injections are in use for treatment of small, bossed, facial hemangiomas. The response to the therapy is equal to response to systemic therapy. The dose of local corticosteroids is $20 \mathrm{mg} / \mathrm{ml}$ in the form of triamcinolone acetonide [58,59]. In 6-8 week intervals, 3-5 injections are needed and during application, surrounding areas must be compressed [59]. Contraindications for local corticosteroids are necrosis and secondary infection of the lesion. Local corticosteroids may be responsible for embolization of small arteries, such as retinal artery, thus their use in cases of eye hemangiomas must be limited [59].

\subsection{Interferons ALFA-2a, ALFA 2-b}

Interferon alfa inhibits the development of new blood vessels from preexisting vessels. Usually therapy with interferon is used when hemangiomas do not respond to the coricosteroid therapy. Daily doses of interferon are 3 million $\mathrm{U} / \mathrm{m}^{2}$ in the form of subcutaneous injections $[56,58]$. Interferon is not a very safe drug. It was shown that it is neurotoxic, thus neurologic follow up is necessary [58]. Also as in the case of systemic corticosteroids, parotic hemangiomas do not respond to their effects [56]. Complications associated with interferon therapy include neutropenia, abnormalities in liver enzymes and spastic diplegia [58].

\subsection{Sclerotherapy}

Sclerotherapy is a procedure in combination with surgery, by which application of some chemicals such as hypertonic saline, sodium tetradecyl sulfate, $5 \%$ ethanolamine oleate, $5 \%$ sodium morrhuate, sodium psylliate, pyngyangmycin, quinine urethrone, $5 \%$ and $1 \%$ polidocanol solutions produce thrombosis of the vessels and an indurated mass [60-62]. The procedure is most effective when the vascular spaces are small or when blood flow is slow [62]. Hemangioma size after sclerotherapy is decreased and its nature changes to a more fibrous consistency, thus surgical resection of the lesion is easily performed with minimal bleeding [61,62]. Complications of sclerotherapy may include ulceration, inflammatory reaction, necrosis and scar, mostly when the sclerosing agent is applied directly to connective tissue or when a vascular leak caused by excessive injection pressure is identified [61].

\subsection{Propranolol}

In 2008. Leaute-Labreze et al.[63] presented efficacy of sympatholytic non-selective beta blocker known as propranolol, in therapy of infantile hemangiomas. The mechanism of action is unknown, but there are reports that suggest that within $24-48$ hours, hemangiomas respond to therapy by size reduction and changes in color [64]. Although authors report that the drug is most effective in cases of proliferative hemangiomas, results of some cases have shown that hemangiomas in the post-proliferative stage respond well [64,65]. A daily dose of propranolol is $2 \mathrm{mg} / \mathrm{kg}$ and it is given in three equally doses [65]. Taking in consider that propranolol is a relatively new drug for treatment of infantile hemangiomas, there is little known of its side effects. For example, while Zvulunov et al. 
[66] report no significant side effects, some other authors suggest that propranolol may mask the clinical signs of early cardiac failure and diminish cardiac performance. Also it may blunt the clinical features of hypoglycemia[67].

\subsection{Imiquimod}

Imiquimod is a drug with ability to induce the production of interferon, tumor necrosis factor-alpha and the antiangiogenesis factor tissue inhibitor of matrix metalloproteinase [68]. In topical form as Imiquimod 5\% cream may be effective in therapy of superficial infantile hemangiomas [69-71]. Some authors suggest that the Imiquimod should be avoided in those hemangiomas located around the cavities and skin folds [69]. The most common side effects of topical Imiquimod are slight skin erythema and crusting [69,70]. Post-treatment skin reactions are texture changes, which in cases without crusting involuted to almost normal skin [70].

\subsection{Bleomycin}

Bleomycin is an antibiotic from the culture medium of streptomyces verticullust, with properties of an anticancer agent [72]. In treatment of infantile hemangiomas, bleomycin in the form of bleomycin A5 may be used isolated [73] or in combination with prednisone [72,73]. As intralesional injection its efficacy is based on a high sclerosing effect on vascular endothelium [74], thus it is most effective in cases of proliferating infantile hemangiomas, inhibiting the proliferation [72]. The results of studies have show a high incidence of complete hemangioma involutions, better recovery of skin color and less scar forming in small hemangiomas, after bleomycin therapy [72-74]. Side effects of therapy include edema, ulceration, gastrointestinal symptoms such as nausea and lack of appetite [72,74], cellulitis and transient hair loss [73].

\section{Conclusion}

Each treatment modality of head and neck located hemangiomas has its own risks and benefits. In cases of infantile hamangiomas, oral propranolol is very useful and well tolerated, having minimal side-effects in the resolution of the hemangiomas. In adult patients surgical treatment including intratumoral ligation, isolated or in combination with laser or sclerotherapy is the most performed therapeutic option.

\section{Acknowledgements}

The authors thank pharmaceutical company Roche d.o.o.-Roche Ltd for article processing charge's support. 


\section{Author details}

Faris Fočo ${ }^{1}$ and Amila Brkić ${ }^{2}$

1 Department of Maxillofacial surgery, Clinical center of University in Sarajevo, Sarajevo, Bosnia and Herzegovina

2 Department of Oral surgery, Faculty of Dentistry, Sarajevo University, Sarajevo, Bosnia and Herzegovina

\section{References}

[1] Richter GT, Friedman AB. Hemangiomas and vascular malformations: current theory and management. Int J Pediatr. 2012;2012:645678. Epub 2012 May 7.

[2] Mulliken JB, Glowacki J. Hemangiomas and vascular malformations in infants and children: a classification based on endothelial characteristics. Plastic and Reconstructive Surgery. 1982;69(3):412-422.

[3] Dilsiz A, Aydin T, Gursan N. Capillary hemangioma as a rare benign tumor of the oral cavity: a case report. Cases Journal 2009, 2:8622 doi:10.4076/1757-1626-2-8622.

[4] Mulliken JB, Fishman SJ, Burrows PE. Vascular anomalies. Curr Probl Surg 2000;37:517-84.

[5] Kocer U, Ozdemir R, Tiftikcioglu YO, Karaaslan O: Soft tissue hemangioma formation within a previously excised intraosseous hemangioma site. J CraniofacSurg 2004; 15:82-83.

[6] Açikgöz A, Sakallioglu U, Ozdamar S, Uysal A: Rare benign tumours of oral cavity-capillary haemangioma of palatal mucosa: a case report. Int J Paediatr Dent 2000, 10:161-165.

[7] Margileth AM, Museles M. Cutaneous hemangiomas in children: Diagnosis and conservative management. JAMA 1965;194:523.8.

[8] Schlosser KA. Infantile hemangioma: how to treat this benign neoplasm of childhood. JAAPA. 2009 May;22(5):46-9.

[9] Neville BW, Damm DD, Allen CM, Bouquot JE: Oral and Maxillofacial Pathology. 2nd edition. WB Saunders; 2002:447-449.

[10] Chang LC, Haggstrom AN, Drolet BA, et al. Growth characteristics of infantile hemangiomas: implications for management. Pediatrics 2008;122:360-7.

[11] Sznajder N, Dominguez FV, Carraro JJ, Lis G: Hemorrhagic hemangioma of gingiva: report of a case. J Periodontol 1973, 44:579-582. 
[12] Gill JS, Gill S, Bhardwaj A, Grover HS. Oral Haemangioma. Case Report Med. 2012; 2012: 347939.

[13] Mulliken JB, Enjolras O. Congenital hemangiomas and infantile hemangioma: missing links. J Am Acad Dermatol. 2004 Jun;50(6):875-82.

[14] Berenguer B, Mulliken JB, Enjolras O, Boon LM, Wassef M, Josset P, Kozakewich HP. Rapidly involuting congenital hemangioma: clinical and histopathologic features. Pediatr Develop Pathol 2003;6:495-510.

[15] Gorincour G, Kokta V, Rypens F, Garel L, Powell J, Dubois J. Imaging characteristics of two subtypes of congenital hemangiomas: rapidly involuting congenital hemangiomas and non-involuting congenital hemangiomas. Pediatr Radiol. 2005 Dec; 35(12):1178-85.

[16] Kleinman ME, Greives MR, Churgin SS, Blechman KM, Chang EI, Ceradini DJ, Tepper OM, Gurtner GC. Hypoxia-induced mediators of stem/progenitor cell trafficking are increased in children with hemangioma. Arterioscler Thromb Vasc Biol. 2007 Dec;27(12):2664-70.

[17] Bischoff J. Progenitor cells in infantile hemangioma. J Craniofac Surg. 2009 Mar;20 Suppl 1:695-7.

[18] Picard A, Boscolo E, Khan ZA, Bartch TC, Mulliken JB, Vazquez MP, Bischoff J. IGF-2 and FLT-1/VEGF-R1 mRNA levels reveal distinctions and similarities between congenital and common infantile hemangioma. Pediatr Res. 2008 Mar;63(3):263-7.

[19] Konez O, Burrows PE, Mulliken JB, Fishman SJ, Kozakewich HPV. Angiographic features of rapidly involuting congenital hemangioma (RICH). Pediatr Radiol (2003) 33: $15-19$.

[20] Browning JC, Metry DW. Rapidly involuting congenital hemangioma: case report and review of the literature. Dermatol Online J. 2008 Apr 15;14(4):11.

[21] Krol A, MacArthur CJ. Congenital hemangiomas: rapidly involuting and non-involuting congenital hemangiomas. BArch Facial Plast Surg 2005;7:307-311.

[22] Enjolras O, Mulliken JB, Boon LM, Wassef M, Kozakewich HP, Burrows PE. Noninvoluting congenital hemangioma: a rare cutaneous vascular anomaly. Plast Reconstr Surg. 2001 Jun;107(7):1647-54.

[23] Barnés CM, Huang S, Kaipainen A, Sanoudou D, Chen EJ, Eichler GS, Guo Y, Yu Y, Ingber DE, Mulliken JB, Beggs AH, Folkman J, Fishman SJ. Evidence by molecular profiling for a placental origin of infantile hemangioma. Proc Natl Acad Sci U S A. 2005 Dec 27;102(52):19097-102.

[24] Pittman KM, Losken HW, Kleinman ME, Marcus JR, Blei F, Gurtner GC, Marchuk DA. No evidence for maternal-fetal microchimerism in infantile hemangioma: a molecular genetic investigation. J Invest Dermatol. 2006 Nov;126(11):2533-8. 
[25] Sun ZY, Yi CG, Zhao H, Yin GQ, Gao M, Liu YB, Qin JD, Wang SF, Guo SZ. Infantile hemangioma is originated from placental trophoblast, fact or fiction? Med Hypotheses. 2008 Sep;71(3):444-8.

[26] Ritter MR, Butschek RA, Friedlander M, Friedlander SF. Pathogenesis of infantile haemangioma: new molecular and cellular insights. Expert Rev Mol Med. 2007;9(32): 1-19.

[27] Chang EI, Chang EI, Thangarajah H, Hamou C, Gurtner GC. Hypoxia, hormones, and endothelial progenitor cells in hemangioma. Lymphat Res Biol. 2007;5(4):237-43.

[28] Sasaki GH, Pang CY, Wittliff JL. Pathogenesis and treatment of infant skin strawberry hemangiomas: clinical and in vitro studies of hormonal effects. Plast Reconstr Surg. 1984; 73: 359-370.

[29] Kleinman ME, Greives MR, Churgin SS, Blechman KM, Chang EI, Ceradini DJ, Tepper OM, Gurtner GC. Hypoxia-induced mediators of stem/progenitor cell trafficking are increased in children with hemangioma. Arterioscler Thromb Vasc Biol. 2007 Dec;27(12):2664-70.

[30] Byrne AM, Bouchier-Hayes DJ, Harmey JH. Angiogenic and cell survival functions of vascular endothelial growth factor (VEGF). J Cell Mol Med. 2005 Oct-Dec;9(4): 777-94.

[31] Przewratil P, Sitkiewicz A, Wyka K, Andrzejewska E. Serum levels of vascular endothelial growth factor and basic fibroblastic growth factor in children with hemangiomas and vascular malformations--preliminary report. Pediatr Dermatol. 2009 JulAug;26(4):399-404.

[32] Przewratil P, Sitkiewicz A, Andrzejewska E. Serum levels of basic fibroblastic growth factor (bFGF) in children with vascular anomalies: Another insight into endothelial growth. Clin Biochem. 2010 Jul;43(10-11):863-7.

[33] Yuan WL, Qin XJ, Wang XK. Expression and correlation of mast cell, Clusterin/apoJ and transforming growth factor-beta in the different stages of human dermal hemangioma. Hua Xi Kou Qiang Yi Xue Za Zhi. 2009 Aug;27(4):361-5.

[34] Walter, JW, et al. Genetic mapping of a novel familial form of infantile hemangioma. Am J Med Genet 1999. 82:77-83.

[35] Blei, F, Walter, J, Orlow, SJ, Marchuk, DA. Familial segregation of hemangiomas and vascular malformations as an autosomal dominant trait: a rare genetic disorder. Arch Dermatol 1998. 134:718-722.

[36] Song JK, Niimi Y, Berenstein A. Endovascular treatment of hemangiomas. Neuroimaging Clin N Am. 2007 May;17(2):165-73.

[37] Walch C, Anderhuber W, Luxenberger W, Humer-Fuchs U Cavernous haemangioma in the infraorbital nerve canal--an unusual expansion in the maxillary sinus J Laryngol Otol. 1998 Sep;112(9):872-4. 
[38] Rachappa MM, Triveni MN. Capillary hemangioma or pyogenic granuloma: A diagnostic dilemma. Contemp Clin Dent. 2010 Apr;1(2):119-22.

[39] Donnelly LF, Adams DM, Bisset GS 3rd. Vascular malformations and hemangiomas: a practical approach in a multidisciplinary clinic. AJR Am J Roentgenol. 2000 Mar; 174(3):597-608.

[40] Li WY, Chaudhry O, Reinisch JF. Guide to early surgical management of lip hemangiomas based on our experience of 214 cases. Plast Reconstr Surg. 2011 Nov;128(5): 1117-24.

[41] Chang CS, Wong A, Rohde CH, Ascherman JA, Wu JK. Management of lip hemangiomas: Minimizing peri-oral scars. J Plast Reconstr Aesthet Surg. 2012 Feb;65(2): 163-8.

[42] Mulliken JB, Rogers GF, Marler JJ. Circular excision of hemangioma and purse-string closure: the smallest possible scar. Plast Reconstr Surg. 2002 Apr 15;109(5):1544-54.

[43] $\mathrm{Wu} \mathrm{JK}$, Rohde $\mathrm{CH}$. Purse-string closure of hemangiomas: early results of a follow-up study. Ann Plast Surg. 2009 May;62(5):581-5.

[44] Vlahovic A, Simic R, Kravljanac D Circular excision and purse-string suture technique in the management of facial hemangiomas. Int J Pediatr Otorhinolaryngol. 2007 Aug;71(8):1311-5.

[45] Popescu V. Intratumoral ligation in the management of orofacial cavernous haemangiomas. J Maxillofac Surg. 1985 Jun;13(3):99-107

[46] Li ZP. Therapeutic coagulation induced in cavernous hemangioma by use of percutaneous copper needles. Plast Reconstr Surg. 1992 Apr;89(4):613-22.

[47] Ogunsalu C, Fray D, Lewis A. Surgery combined with copper wire implantation in the management of cavernous orofacial haemangiomas. Aust Dent J. 2000 Mar;45(1): $55-60$

[48] Apfelberg DB, Maser MR, Lash HReview of usage of argon and carbon dioxide lasers for pediatric hemangiomas. Ann Plast Surg. 1984 Apr;12(4):353-60.

[49] Vesnaver A, Dovsak DA. Treatment of large vascular lesions in the orofacial region with the Nd:YAG laser. J Craniomaxillofac Surg. 2009 Jun;37(4):191-5.

[50] Vesnaver A, Dovsak DA. Treatment of vascular lesions in the head and neck using Nd:YAG laser. J Craniomaxillofac Surg. 2006 Jan;34(1):17-24.

[51] Chang CJ, Fisher DM, Chen YR. Intralesional photocoagulation of vascular anomalies of the tongue. Br J Plast Surg. 1999 Apr;52(3):178-81.

[52] Clymer MA, Fortune DS, Reinisch L, Toriumi DM, Werkhaven JA, Ries WR Interstitial Nd:YAG photocoagulation for vascular malformations and hemangiomas in childhood. Arch Otolaryngol Head Neck Surg. 1998 Apr;124(4):431-6. 
[53] Burstein FD, Simms C, Cohen SR, Williams JK, Paschal M. Intralesional laser therapy of extensive hemangiomas in 100 consecutive pediatric patients. Ann Plast Surg. 2000 Feb;44(2):188-94.

[54] Greenberger S, Boscolo E, Adini I, Mulliken JB, Bischoff J. Corticosteroid Suppression of VEGF-A in Infantile Hemangioma-Derived Stem Cells.N Engl J Med 2010; 362:1005-1013.

[55] Sadan N, Wolach B. Treatment of hemangiomas of infants with high doses of prednisone. J Pediatr 1996; 128(1):141-6.

[56] Blei F, Isakoff M, Deb G. The Response of Parotid Hemangiomas to the Use of Systemic Interferon Alfa-2a or Corticosteroids. Arch Otolaryngol Head Neck Surg. 1997;123(8):841-844.

[57] Bennett M, Fleischer, Jr AB, Chamlin SL, Frieden IJ. Oral Corticosteroid Use Is Effective for Cutaneous Hemangiomas: An Evidence-Based Evaluation. Arch Dermatol. 2001;137(9):1208-1213.

[58] Drolet BA, Esterly NB, Frieden IJ. Hemangiomas in children. N Engl J Med 1999; 341(3):173-81.

[59] Roberts LJ. Management of hemangiomas. Pediatr Dermatol 1997; 14(1):57-83.

[60] Levy C, Mandel L. Sclerotherapy of intraoral hemangioma. N Y State Dent J. 2012 Apr;78(3):19-21.

[61] Selim H, Selim A, Khachemoune A, Metwally SA. Use of sclerosing agent in the management of oral and perioral hemangiomas: review and case reports. Med Sci Monit. 2007 Sep;13(9):CS114-119.

[62] Choi $\mathrm{YH}, \mathrm{Han} \mathrm{MH}, \mathrm{O}-\mathrm{Ki} \mathrm{K}$ et al: Craniofacial cavernous venous malformations: percutaneous sclerotherapy with use of ethanolamine oleate. J Vasc Interv Radiol, 2002; 13: 475-82.

[63] Leaute-Labreze C, Dumas de la Roque E, Hubiche T, Boralevi F, Thambo J-B, Taieb A. Propranolol for severe hemangiomas of infancy. N Engl J Med 2008;358:2649-51.

[64] Bertrand J, Sammour R, McCuaig C, Dubois J, Hatami A, Ondrejchak S, Boutin C, Bortoluzzi P, Laberge LC, Powell J. Propranolol in the treatment of problematic infantile hemangioma: review of 35 consecutive patients from a vascular anomalies clinic. J Cutan Med Surg. 2012 Mar-Apr;16(2):115-21.

[65] Guldbakke KK, Rørdam OM, Huldt-Nystrøm T, Hanssen HK, Høivik F. Propanolol used in treatment of infantile hemangioma. Tidsskr Nor Laegeforen. 2010 Sep 23;130(18):1822-4.

[66] Zvulunov A, McCuaig C, Frieden IJ, Mancini AJ, Puttgen KB, Dohil M, Fischer G, Powell J, Cohen B, Ben Amitai D. Oral propranolol therapy for infantile hemangiomas beyond the proliferation phase: a multicenter retrospective study. Pediatr Dermatol. 2011 Mar-Apr;28(2):94-8. 
[67] Siegfried EC, Keenan WJ, Al-Jureidini S. More on propranolol for hemangiomas of infancy. N Engl J Med. 2008 Dec 25;359(26):2846; author reply 2846-7.

[68] Ho NT, Lansang P, Pope E. Topical imiquimod in the treatment of infantile hemangiomas: a retrospective study. J Am Acad Dermatol. 2007 Jan;56(1):63-8.

[69] Ma G, Lin XX, Jiang CH, Chen H, Li W, Hu XJ, Jin YB, Chen D, Chen XD, Ye XX. Clinical application of imiquimod for the treatment of infantile hemangiomas. Zhonghua Zheng Xing Wai Ke Za Zhi. 2011 Nov;27(6):411-4.

[70] Jiang C, Hu X, Ma G, Chen D, Jin Y, Chen H, Chen X, Lin X. A prospective self-controlled phase II study of imiquimod $5 \%$ cream in the treatment of infantile hemangioma. Pediatr Dermatol. 2011 May-Jun;28(3):259-66.

[71] Barry RB, Hughes BR, Cook LJ. Involution of infantile haemangiomas after imiqui$\bmod$ 5\% cream. Clin Exp Dermatol. 2008 Jul;33(4):446-9.

[72] Luo QF, Zhao FY. The effects of Bleomycin A5 on infantile maxillofacial haemangioma. Head Face Med. 2011 Jul 7;7:11.

[73] Luo Q, Zhao F. How to use bleomycin A5 for infantile maxillofacial haemangiomas: clinical evaluation of 82 consecutive cases. J Craniomaxillofac Surg. 2011 Oct;39(7): 482-6.

[74] Muir T, Kirsten M, Fourie P, Dippenaar N, Ionescu GO. Intralesional bleomycin injection (IBI) treatment for haemangiomas and congenital vascular malformations. Pediatr Surg Int. 2004 Jan;19(12):766-73. 
